\title{
Significance of Bcl10 gene mutations in the clinical diagnosis of MALT-type ocular adnexal lymphoma in the Chinese population
}

\author{
J. Zhu ${ }^{1}$, R.L. Wei ${ }^{2}$, Y.L. Pi ${ }^{1}$ and Q. Guo ${ }^{1}$ \\ ${ }^{1}$ Department of Ophthalmology, \\ ${ }^{2}$ Department of Ophthalmology, Changzheng Hospital, \\ Second Military Medical University, Shanghai, China \\ Corresponding author: J. Zhu \\ E-mail: zhujing-301@163.com \\ Genet. Mol. Res. 12 (2): 1194-1204 (2013) \\ Received July 26, 2012 \\ Accepted January 5, 2013 \\ Published April 12, 2013 \\ DOI http://dx.doi.org/10.4238/2013.April.12.6
} First Affiliated Hospital of the Chinese PLA General Hospital, Beijing, China

\begin{abstract}
We investigated the expression of Bcl10 gene mutations in mucosa-associated lymphoid tissue-type ocular adnexal lymphoma $(\mathrm{OAL})$, atypical lymphoid hyperplasia (ALH), and reactive lymphoid hyperplasia (RLH) in the Chinese population and its role in clinical diagnosis and pathogenesis. Forty-three samples were collected during patient surgeries. Pathological diagnosis confirmed OAL in 23 cases, ALH in 10 cases, and RLH in 10 cases. Normal peripheral lymph tissues from 12 cases were used as negative controls. Bcl10 gene expression was examined using molecular biological methods, and DNA sequences and mutations were compared with published data. The protein expression of $\mathrm{Bcl10}$ and nuclear factor kappaB (NF-kB) were detected with immunohistological and immunofluorescence colocalization. Bcl10 gene expression was detected in $15 \mathrm{OAL}$ cases. Novel mutations were found in 11 cases. Notably, 1 mutation, which matched a published mutation, was detected in 1 ALH case; 1 novel mutation was found in 1 RLH case; and no Bcl10 gene mutation was found in controls. Most novel mutations were
\end{abstract}


truncation mutations, resulting in a truncated protein product of 99 amino acids (compared to the full-length 233 amino acids; GenBank accession No. EF189176). Results of tests for abnormal Bcl10 gene expression in nuclei or cytoplasm were consistent with changes in NF- $\mathrm{kB}$ translocation. This report is the first of newly discovered mutations in the Bcl10 gene in the Chinese population. The distribution of the mutations is consistent with and more sensitive than that of the pathological diagnosis. These mutations can be used to identify the stage and clinical characteristics even when morphological changes are absent.

Key words: Bcl10 gene; Eye tumor; Lymphoma; Diagnosis; Mucosa-associated lymphatic tissue

\section{INTRODUCTION}

Mucosa-associated lymphoid tissue (MALT)-type ocular adnexal lymphoma (OAL) frequently occurs outside of the lymph nodes of marginal zone MALT lymphoma, accounting for $15 \%$ of all orbital solid tumors (Thieblemont et al., 1997). It is the most common type of OAL and is similar to lymphoproliferative lesions such as reactive lymphoid hyperplasia (RLH). During clinical diagnosis, determination of the course and type of disease using solely clinical manifestations is often difficult (Misdraji et al., 2011). Pathologically, the morphology is difficult to identify microscopically in some borderline atypical lesions, which affects therapy and prognosis. In 1999, Willis et al. first reported a $\mathrm{t}(1 ; 14)(\mathrm{p} 22 ; \mathrm{q} 32)$ translocation that led to Bcl10 gene cloning and expression of various Bcl10 mutations and descriptions of their biological significance in MALT lymphoma and other types of tumors. The structure of wild-type Bcl10 and its tumor-suppressive functions have also been described in detail. The mutations and corresponding changes in biological behavior have been attributed to a signal transduction pathway that suppresses apoptosis of tumor cells (Rosebeck et al., 2011). A study of low-grade gastric MALT lymphoma by Du et al. (2000) found mutations of Bcl10 in 3 of 11 tumors that were unresponsive to Helicobacter pylori eradication therapy, but none was found in 22 tumors that regressed completely after the same treatment. However, the significance of Bcl10 in OAL, differences in the mutation in Chinese people, and its significance and association related to clinical diagnosis have not been reported. In this study, we first detected the existence of Bcl10 in Chinese patients with OAL, found novel mutation sites, identified novel mutations in the Bcl10 gene, and investigated their relationships with the activation of nuclear factor-kappaB (NF-kB). Our aim was to assess the value of novel Bcl10 gene mutations in the diagnosis of MALT lymphoma and to provide new evidence for the role of the Bcl10-activated NF-KB pathway in the development of MALT lymphoma.

\section{MATERIAL AND METHODS}

\section{Subjects}

Informed consent was obtained from all subjects, and the study was approved by the Ethics Committee of China. All subjects were recruited between 2008 and 2011 from the Ophthalmology Department at the First Affiliated Hospital of Chinese PLA General Hospital 
and Changzheng Hospital, Second Military Medical University. Included in the study were 23 patients with OAL, 10 with atypical lymphoid hyperplasia (ALH), 10 with RLH, and 12 individuals with normal peripheral lymph tissue. The diagnoses were confirmed by 2 independent pathologists using a double-blind method according to the World Health Organization classification of myeloid tumors in the hematologic system (Rohatiner et al., 1994). All samples were obtained during surgery and stored in liquid nitrogen.

\section{Histopathological assay and immunostaining}

The histological material fixed in 10\% formalin and embedded in paraffin was cut into $4-\mu \mathrm{m}$ sections. After deparaffinization, the sections underwent hematoxylin and eosin staining for histopathological assay. The avidin-biotin-immunoperoxidase technique was used as outlined in a previous study (Willis et al., 1999). Antigen retrieval was performed after hydration and endogenous peroxidase blocking with $3 \%$ hydrogen peroxide at $90^{\circ} \mathrm{C}$ for $30 \mathrm{~min}$. The sections were then incubated for $30 \mathrm{~min}$ at room temperature with anti-CD45RO (1:200) and anti-CD3 (1:100) for T-cell labeling, with anti-CD20 and anti-CD79a (1:100) for B-cell labeling, with anti-immunoglobulin $\kappa$ and $\lambda$ light-chain $(1: 200)$ for discriminating benign lymphoid hyperplasia from MALT lymphoma, with anti-bcl2 and Ki-67 (1:50) to determine proliferation, and with anti-Bcl10 to identify Bcl10 gene expression products.

The evaluation of immunostaining was as follows: CD20, CD79a, and CD45RO stained the membrane yellow-brown; $\mathrm{CD} 3, \kappa$, and $\lambda$ stained cytoplasts in a diffuse yellow-brown; and Bcl2 and Ki-67 stained the nucleus yellow-brown. The positive staining index was the percentage of positive cells among 1000 cancer cells under 5 high-power visual fields. The staining was scored as follows: positive cells $<5 \%(-), 5-24 \%(+), 25-49 \%(++), 50-74 \%(+++)$, and $\geq 75 \%(++++)$.

\section{Immunofluorescence colocalization}

We used 4- $\mu$ m-thick optical sections for immunofluorescence colocalization. After blocking, the sections were exposed to fluorescein isothiocyanate-labeled Bcl10 antibody (1:100 green), CY3-labeled Iк $\alpha$ antibody (red), and 4',6-diamidino-2-phenylindole (blue) for staining nuclei (1:50). The sections were examined using a Leica TCS SP2 microscope (Leica Co., Ltd., German) and the LSM 510 Image Browser software (Leica Co., Ltd.).

\section{DNA sequencing and mutation detection}

Total RNA was isolated from frozen tumor tissues using a phenol/chloroform method, and RNA purity was assessed with spectrophotometry $\left(\mathrm{A}_{260} / \mathrm{A}_{280}>1.8\right)$. Complementary DNA was synthesized from total RNA ranging from 50 to $500 \mathrm{ng}$ in a $10-\mu \mathrm{L}$ reaction mixture using a reverse transcription-polymerase chain reaction (RT-PCR) kit (Beijing TransGen Biotech Co. Ltd., Beijing, China) according to manufacturer instructions. Twenty microliters of PCR mixture contained $1 \mu \mathrm{L}$ RT product as a template, PCR buffer, $2 \mathrm{mM} \mathrm{MgCl}, 1.25 \mathrm{U} / 50 \mathrm{~mL}$ DNA polymerase, and $0.15 \mathrm{mM}$ primers. The primer sequences were designed according to the Bcl10 gene and synthesized by Shanghai Sangon Biotechnology Co., Ltd. (Shanghai, China). We amplified $\beta$-actin as an internal control. The PCR conditions were an initial denaturing at $95^{\circ} \mathrm{C}$ for $5 \mathrm{~min}$; followed by 35 cycles of $94^{\circ} \mathrm{C}$ for $40 \mathrm{~s}, 60^{\circ} \mathrm{C}$ for $40 \mathrm{~s}$, and $72^{\circ} \mathrm{C}$ for $60 \mathrm{~s}$; a final extension at $72^{\circ} \mathrm{C}$ 
for $7 \mathrm{~min}$; and a final hold on ice. These conditions produced the initial amount of total RNA used in the RT reaction. PCR products were examined on a 1\% agarose gel. A 700-800-bp Bcl10 fragment was confirmed under ultraviolet light after ethidium bromide staining.

\section{Sequence analysis}

The purified PCR products were ligated into a PMD18-T vector, and the resultant ligation products were transformed into BL21 Escherichia coli competent cells. The positive clones were confirmed with restriction enzymes, sequenced using a PRISM ${ }^{\mathrm{TM}} 3700$ DNA automatic sequencer (ABI Prism ${ }^{\mathrm{Tm}}$ BigDye $^{\mathrm{Tm}}$ Terminator Cycles Sequencing Ready Reaction Kit), and analyzed with the BLAST software (Invitrogen, Shanghai).

\section{Statistical analysis}

The SPSS10.0 statistical package (SPSS Incorporated, Chicago, USA) was used for all analyses. The variables were examined using the Fisher exact test. A P value of $<0.05$ was considered to be statistically significant.

\section{RESULTS}

\section{Nucleotide sequence mutations and functional protein domain mutants}

Of the 43 cases studied, 21 displayed Bcl10 gene expression. Compared with the published mutation sequences, sequences from 12 cases contained novel mutations (Table 1). After analysis and comparison using the BLAST software, the significant mutations were as follows: 129-bp deletion at nucleotide 294 in the exon, resulting in a truncated protein product of 99 amino acids compared with the full-length protein of 233 amino acids. We registered this mutation in GenBank (accession No. EF189176). Four additional specimens had the same mutation, i.e., a $\mathrm{G} \rightarrow \mathrm{A}$ transversion at nucleotide 638 in the exon, changing Gly 213 to Glu. This point mutation was also detected in $1 \mathrm{RLH}$ case. A T $\rightarrow$ C point mutation at nucleotide 308 in the exon changed Val 103 to Ala in the protein-coding region; a $\mathrm{T} \rightarrow \mathrm{C}$ point mutation at nucleotide 368 in the exon changed Glu 123 to Gly; an $\mathrm{A} \rightarrow \mathrm{G}$ point mutation at nucleotide 374 in the exon changed Ben 125 to Cyp; a $\mathrm{T} \rightarrow \mathrm{C}$ point mutation at nucleotide 5 in the exon changed Glu 2 to Gly; and a $\mathrm{T} \rightarrow \mathrm{C}$ point mutation at nucleotide 412 in the exon changed Val 103 to Ala. An $\mathrm{A} \rightarrow \mathrm{G}$ point mutation at nucleotide 145 in the exon has been reported previously (Willis et al., 1999).

Four of the 10 atypical ALH specimens were positive for Bcl10: a 33-bp deletion at nucleotide 346 in exon truncated the protein from 126 to 116 amino acids. This case presented a different spliceosome of messenger RNA from other specimens, and these mutations had been reported previously. Bcl10 gene expression was detected in 2 cases of RLH, 1 of which displayed the same mutations found in 4 cases described above in ALH cases. No Bcl10 gene expression was detected in the 12 normal peripheral lymph tissues. A significant difference was found between Bcl10 expression rates in the experimental group and that in the control group $(\mathrm{P}<0.05)$. The $\mathrm{Bcl1} 0$ mutation rate varied significantly in lesions with different degrees of malignancy $(\mathrm{P}<0.05)$. No significant difference was found in $\mathrm{Bcl} 10$ mutation rates between different locations and different clinical stages $(\mathrm{P}>0.05)$. 


\begin{tabular}{|c|c|c|c|c|c|c|}
\hline Tumor & Case No. & Alteration & Codon & $\begin{array}{l}\text { Mutation } \\
\text { type }\end{array}$ & $\begin{array}{c}\text { Predicted } \\
\text { protein size } \\
\text { (amino acids) }\end{array}$ & Published type \\
\hline \multirow{15}{*}{ MALT lymphoma } & $6-2-9-1$ & $308 \mathrm{~T} \rightarrow \mathrm{C}$ & 103 & $\mathrm{Val} \rightarrow \mathrm{Ala}$ & 233 & Novel mutation \\
\hline & $3-2-9-5$ & $638 \mathrm{G} \rightarrow \mathrm{A}$ & 213 & Gly $\rightarrow$ Glu & 233 & Novel mutation \\
\hline & $1-12$ & $638 \mathrm{G} \rightarrow \mathrm{A}$ & 213 & Gly $\rightarrow$ Glu & 233 & Novel mutation \\
\hline & $2-28$ & $638 \mathrm{G} \rightarrow \mathrm{A}$ & 213 & Gly $\rightarrow$ Glu & 233 & Novel mutation \\
\hline & $6-10$ & $638 \mathrm{G} \rightarrow \mathrm{A}$ & 213 & Gly $\rightarrow$ Glu & 233 & Novel mutation \\
\hline & $10-2$ & 294del129 & 99 & Truncation & 109 & Registration \\
\hline & $4-20$ & $368 \mathrm{~T} \rightarrow \mathrm{C}$ & 123 & Glu $\rightarrow$ Gly & 233 & Novel mutation \\
\hline & $5-14$ & $145 \mathrm{~A} \rightarrow \mathrm{G}$ & 49 & $\mathrm{Arg} \rightarrow \mathrm{Gly}$ & 157 & Published* \\
\hline & $6-25$ & $374 \mathrm{~A} \rightarrow \mathrm{G}$ & 125 & $\mathrm{Phe} \rightarrow \mathrm{Ser}$ & 233 & Novel mutation \\
\hline & $7-13$ & $5 \mathrm{~T} \rightarrow \mathrm{C}$ & 2 & Glu $\rightarrow$ Gly & 233 & Nonsense mutation \\
\hline & $8-20$ & $412 \mathrm{~T} \rightarrow \mathrm{C}$ & 103 & $\mathrm{Val} \rightarrow$ Ala & 233 & Novel mutation \\
\hline & $3-21$ & $186 \mathrm{~A} \rightarrow \mathrm{G}$ & 62 & $\operatorname{Arg} \rightarrow \operatorname{Arg}$ & 233 & Nonsense mutation \\
\hline & A1-11-29 & Normal & Full-length amino acids & None & 233 & \\
\hline & $\mathrm{L}-\mathrm{C}$ & Normal & Full-length amino acids & None & 233 & \\
\hline & $8-11$ & Normal & Full-length amino acids & None & 233 & \\
\hline \multirow[t]{2}{*}{ Reactive lymphoid hyperplasia } & $10-25$ & $638 \mathrm{G} \rightarrow \mathrm{A}$ & 213 & Gly $\rightarrow$ Glu & 233 & Novel mutation \\
\hline & $11-5$ & Normal & Full-length amino acids & None & 233 & \\
\hline \multirow[t]{4}{*}{ Atypical lymphoid hyperplasia } & $10-5$ & 346del33 & $116-126$ & Splice aberration & 157 & Published* \\
\hline & $\mathrm{Xu}-1$ & Normal & Full-length amino acids & None & 233 & \\
\hline & $4-20$ & Normal & Full-length amino acids & None & 233 & \\
\hline & $5-11$ & Normal & Full-length amino acids & None & 233 & \\
\hline
\end{tabular}

*Other several types.

\section{Pathological features and immunophenotype of OAL}

Of 23 patients with MALT lymphoma, 12 had lymphoid follicles. Compared with normal tissue, the residual germinal center in these cases was small and the cap was absent. Monotonous infiltration formed by a few centrocyte-like cells and immune blood cells was seen. The tumor cells displayed diffuse distribution with small cell volume, wide cytoplasts, and nuclei with cell-like or monocyte-like germinal center differentiation. No lymphoepithelial lesions were found. Three cases displayed combined infiltrated vessels and fat tissues. One case of ALH consisted mainly of mature lymphocytes, and the cells showed diversity. Sporadic plasmocytes, histiocytes, and immune blood cells were also seen. Of the 10 RLH cases, 1 featured normal follicle structure, small lymphocyte proliferation, and plasmocyte infiltration. Immunohistochemical analysis revealed CD20 (+), CD79a (+); CD3 (-), CD45RO (-). Five cases were immunoglobulin $\kappa$ lightchain positive, and 2 cases were $\lambda$ light-chain positive. Four cases were Bcl-2 positive $(++)$; 3 cases, Bcl-2 positive (+); and 1 case, Bcl-2 negative (-). The Ki-67 proliferation rate was $>10 \%$ in 4 cases.

Twenty (86.96\%) of the 23 MALT specimens were Bcl10 positive, including 13 cases $(65.0 \%)$ positive in both the nucleus and the cytoplasm and 7 cases $(35.0 \%)$ positive only in the cytoplasm (Figure 1). Five (50\%) of the 10 atypical lymphatic hyperplasia specimens had diffuse Bcl10 expression in the cytoplasm. One case (10\%) Bcl10 expression was positive in both the nucleus and the cytoplasm, and $3(30 \%)$ of the 10 RLH specimens displayed Bcl10 expression in the cytoplasm. All control specimens were Bcl10 negative. The nuclear expression of the Bcl10 protein was significantly correlated with mutation of the Bcl10 gene $(\mathrm{P}<0.05)$. The expression of the Bcl10 protein was not significantly different in lesions with various degrees of malignancy $(\mathrm{P}>0.05)$. Eighteen $(78.3 \%)$ of the 23 MALT specimens were 
$\mathrm{NF}-\kappa \mathrm{B}$ positive both in the nucleus and the cytoplasm, and 5 cases $(21.7 \%)$ were positive only in the cytoplasm. Seven (70\%) of the 10 ALH specimens had diffuse NF- $\mathrm{KB}$ expression in the cytoplasm. One case (10\%) was NF-кB positive in both the nucleus and the cytoplasm, and 5 $(50 \%)$ of the 10 RLH specimens displayed NF- $\kappa$ B expression in the cytoplasm.

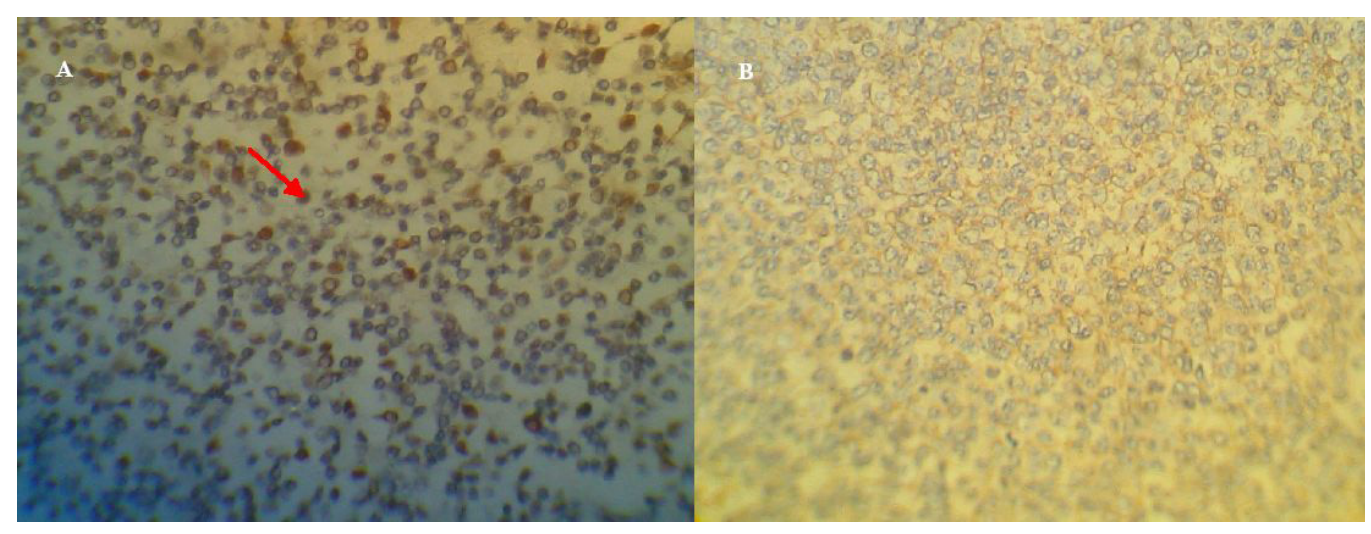

Figure 1. A. Bcl10 expression in tumor cell nuclei. B. Nuclear factor-kappaB expression in tumor cell nuclei and cytoplasm.

In the control group, all specimens had diffuse NF- $\kappa \mathrm{B}$ expression in the cytoplasm. The positive rates of the NF- $\mathrm{KB}$ protein in MALT-type OAL, ALH, and RLH were significantly different $(\mathrm{P}<0.05)$. The nuclear expression of the Bcl10 protein was significantly correlated with the expression of NF- $\mathrm{kB}(\mathrm{P}<0.05)$.

\section{Bcl10 gene mutation in MALT-type OAL, ALH, and RLH}

Of 43 OAL cases, the Bcl10 gene cDNA was detected in 15 cases with MALT, and novel mutations were found in 11 cases. The mutation-positive rate was $73.33 \%$. Bcl10 mutation was detected in $1 \mathrm{ALH}$ case, and had been reported previously. A novel Bcl10 mutation was detected in 1 RLH case. The 12 cases with normal lymph tissues showed no Bcl10 expression (Table 2). The Fisher exact test showed that the differences in Bcl10 gene mutation were statistically significant among the cases with MALT lymphoma, ALH, RLH, and normal lymph tissue.

\section{Colocalization of the Bcl10 gene and NF-кB}

The signals of a laser-scanning confocal microscope were subjected to 3-D reconstruction using the SFP option. Fluorescein isothiocyanate-labeled Bcl10 protein was distributed in the nucleus and cytoplasm in a dotted manner or in clusters of green fluorescence granules. $\mathrm{Cy} 3-$ labeled NF- $\mathrm{KB}$ protein was widely distributed in the cytoplasm. The reconstructed image showed colocalization of the yellow fluorescence of Bcl10 and NF-kB, including 14 cases of $\mathrm{Bcl10}$ and NF- $\mathrm{\kappa B}$ coexpression (Figure 2). The expression of Bcl10 was positively correlated with that of NF- $\mathrm{KB}(\mathrm{P}<0.05)$. 


\begin{tabular}{|c|c|c|c|c|c|c|}
\hline Tumor & Case No. & Alteration & Codon & Mutation type & $\begin{array}{c}\text { Predicted } \\
\text { protein size } \\
\text { (amino acids) }\end{array}$ & Published type \\
\hline \multirow[t]{15}{*}{ MALT lymphoma } & $6-2-9-1$ & $308 \mathrm{~T} \rightarrow \mathrm{C}$ & 103 & $\mathrm{Val} \rightarrow \mathrm{Ala}$ & 233 & Novel mutation \\
\hline & $3-2-9-5$ & $638 \mathrm{G} \rightarrow \mathrm{A}$ & 213 & Gly $\rightarrow$ Glu & 233 & Novel mutation \\
\hline & $1-12$ & $638 \mathrm{G} \rightarrow \mathrm{A}$ & 213 & Gly $\rightarrow$ Glu & 233 & Novel mutation \\
\hline & $2-28$ & $638 \mathrm{G} \rightarrow \mathrm{A}$ & 213 & Gly $\rightarrow$ Glu & 233 & Novel mutation \\
\hline & $6-10$ & $638 \mathrm{G} \rightarrow \mathrm{A}$ & 213 & Gly $\rightarrow$ Glu & 233 & Novel mutation \\
\hline & $10-2$ & 294del129 & 99 & Truncation & 109 & Registration \\
\hline & $4-20$ & $368 \mathrm{~T} \rightarrow \mathrm{C}$ & 123 & Glu $\rightarrow$ Gly & 233 & Novel mutation \\
\hline & $5-14$ & $145 \mathrm{~A} \rightarrow \mathrm{G}$ & 49 & $\mathrm{Arg} \rightarrow$ Gly & 157 & Published* \\
\hline & $6-25$ & $374 \mathrm{~A} \rightarrow \mathrm{G}$ & 125 & $\mathrm{Phe} \rightarrow \mathrm{Ser}$ & 233 & Novel mutation \\
\hline & $7-13$ & $5 \mathrm{~T} \rightarrow \mathrm{C}$ & 2 & $\mathrm{Glu} \rightarrow \mathrm{Gly}$ & 233 & Nonsense mutation \\
\hline & $8-20$ & $412 \mathrm{~T} \rightarrow \mathrm{C}$ & 103 & $\mathrm{Val} \rightarrow \mathrm{Ala}$ & 233 & Novel mutation \\
\hline & $3-21$ & $186 \mathrm{~A} \rightarrow \mathrm{G}$ & 62 & $\operatorname{Arg} \rightarrow \operatorname{Arg}$ & 233 & Nonsense mutation \\
\hline & A1-11-29 & Normal & Full-length amino acids & None & 233 & \\
\hline & $\mathrm{L}-\mathrm{C}$ & Normal & Full-length amino acids & None & 233 & \\
\hline & $8-11$ & Normal & Full-length amino acids & None & 233 & \\
\hline \multirow[t]{2}{*}{ Reactive lymphoid hyperplasia } & $10-25$ & $638 \mathrm{G} \rightarrow \mathrm{A}$ & 213 & Gly $\rightarrow$ Glu & 233 & Novel mutation \\
\hline & $11-5$ & Normal & Full-length amino acids & None & 233 & \\
\hline \multirow[t]{4}{*}{ Atypical lymphoid hyperplasia } & $10-5$ & 346del33 & $116-126$ & Splice aberration & 157 & Published* \\
\hline & $\mathrm{Xu}-1$ & Normal & Full-length amino acids & None & 233 & \\
\hline & $4-20$ & Normal & Full-length amino acids & None & 233 & \\
\hline & $5-11$ & Normal & Full-length amino acids & None & 233 & \\
\hline
\end{tabular}

*Other several types.

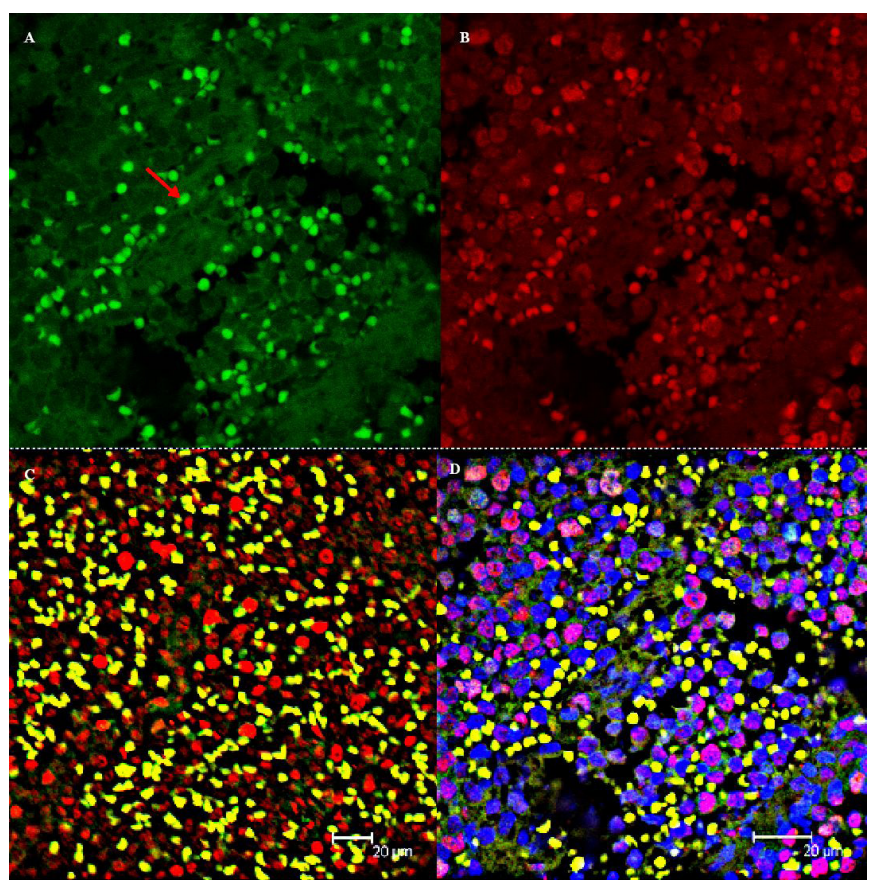

Figure 2. A. Bcl10 protein is indicated by punctate bright-green fluorescent particles distributed in the nucleus and cytoplasm. B. NF-kappaB protein is indicated by diffuse bright-red fluorescence widely distributed in the nucleus and cytoplasm. C. Overlapping images: visible yellow fluorescence for the double expression of Bcl10 green fluorescence and the red fluorescence of NF-kappaB. D. 4',6-Diamidino-2-phenylindole staining of nuclear superimposed images. The orange fluorescence indicates NF-kappaB expression in the nucleus. 


\section{DISCUSSION}

Bc110, an intracellular protein, is homologue of the equine herpesvirus-2 E10 gene. The 233-amino acid BCL10 protein promotes apoptosis under certain physiological conditions (Wu and Ashwell, 2008). It contains a single N-terminal caspase activation and recruitment domain (CARD) containing antiparallel $\alpha$-helices similar to those seen in the "death domain" and a serine/threonine-rich C-terminus (Zhou et al., 2004). The Bcl10 gene has been cloned from the breakpoint region of $\mathrm{t}(1 ; 14)(\mathrm{p} 22 ; \mathrm{q} 32)$ (Willis et al., 1999) and is considered an apoptosis-associated gene involved in NF-kB signal pathway activation. The CARD of Bcl10-mediated self-oligomerization triggers the ubiquitin of mucosa-associated lymphoid

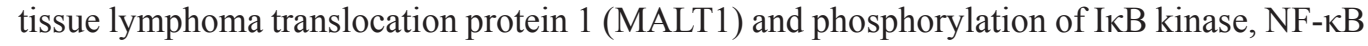
activation, and $\mathrm{\kappa B}$ translocation into the nucleus.

Ye et al. (2005) reported that $\mathrm{t}(14 ; 18)(\mathrm{q} 32 ; \mathrm{q} 21)$ is characterized by strong cytoplasmic MALT1 and Bcl10 expression, and $\mathrm{t}(1 ; 14)(\mathrm{q} 22 ; \mathrm{q} 32)$ is characterized by weak cytoplasmic MALT1 and strong nuclear Bcl10 expression. However, the nuclear expression of Bcl10 is closely related to the AP12-MALT1 fusion protein induced by $\mathrm{t}(11 ; 18)(\mathrm{q} 21 ; \mathrm{q} 21)$ (Sagaert et al., 2007) and clinical disease stage (Coupland, 2004). Therefore, Bcl10 expression is closely related to the genesis and development of MALT lymphoma and plays a key role in chromosomal variation. Bcl10 is considered a marker protein in MALT lymphoma (Marcus, 2007). It can specifically link with lymphocyte receptors through CARD11/lipid rafts, subsequently adjusting the oligomerization of MALT1 to form a complex via oligomerization of the N-terminal CARD without upstream signaling (Sun and Yang, 2010). It activates downstream NF- $\mathrm{kB}$ signaling via unknown molecular mechanisms, causing abnormal NF- $\mathrm{KB}$ translocation in the nucleus that regulates cell apoptosis and changes in lymphocyte proliferation (Hamoudi et al., 2010). Therefore, Bcl10 plays a very important role in the pathogenesis of MALT lymphoma.

The Bcl10 gene mutation leads to the insertion, deletion, and substitution of single nucleotides presenting as frameshift mutations of the open reading frame, predicting positions of stop codons, and truncating the C-terminal region of CARD. Although Bcl10 gene mutation can activate the NF- $\mathrm{kB}$ pathway, it loses the capability to adjust apoptosis and gains carcinogenic capabilities, resulting in the formation and proliferation of MALT lymphoma cells (Kingeter and Schaefer, 2010). The mutation and nuclear expression of Bcl10 activate the NF- $\kappa B$ signal pathway and play a central role in tumorigenesis of MALT lymphoma (Du, 2011). The activation of the NF- $\mathrm{BB}$ signal pathway by Bcl10 leads to the degradation of ІкB phosphorylation, translocation into the nucleus, and changes in gene transcription - important mechanisms in MALT lymphoma.

In this study, samples were harvested during surgery and frozen in liquid nitrogen. The pathological diagnoses were MALT-type OAL, ALH, and RLH. In clinical diagnosis, distinguishing MALT-type OAL from orbital lymphoid tissue nonspecific hyperplasia, inflammatory pseudotumors, and other orbital disease is challenging because their clinical presentations are similar; however, their therapy methods and patient prognoses are quite different. Therefore, accurate and significant differential diagnosis is extremely important.

A palpable mass was the most obvious characteristic among the 23 cases of pathologically diagnosed MALT lymphoma, 10 ALH cases, and 10 RLH cases. No significant difference in clinical indexes was found among the cases. The clinical presentation served only as a reference, and the diagnosis depended mainly on imaging features obtained before surgery 
and the report on pathological morphology that followed. However, pathological diagnosis involves mainly the identification of morphology, and the naked eye cannot discern or diagnose atypical boundary diseases or fine changes at early disease stages, especially in cells with immature cell morphology that have not developed typical MALT lymphoma characteristics, such as follicle colonization, lymphoepithelial lesions, and so on (McKelvie, 2010).

In the 23 cases of MALT lymphoma, only 12 presented as typical follicle colonization microscopically. Center cell-like cell infiltration and cap disappearance were seen, normal and colonized follicles coexisted in 5 cases, and diffusely distributed tumor cells without folliclelike structure were seen in 6 cases. With only clinical manifestations and pathological data, diagnoses are easily missed. This study implemented RT-PCR to amplify the Bcl10 gene and detect mutations in each sample. These data are more sensitive than pathological information in determining tumor processes, identifying early boundary diseases and their malignant degrees, and predicting prognoses. In the 10 RLH cases, follicle structure and mature lymphocyte infiltration were seen under a light microscope, but only 1 case displayed novel Bcl10 mutation on RT-PCR and sequencing analysis, indicating that this case had boundary changes from RLH to MALT lymphoma. The biological behavior revealed functional changes at the genetic level, but these changes could not be identified by the naked eye in pathological morphology to make a final diagnosis. This case should be treated as a malignant tumor; surgery should be performed to incise the tumor and part of the surrounding tissue; and local radiotherapy and chemotherapy should be administered for better treatment effects and refined prognoses.

Similarly, in 1 ALH case, pathological assay could not exclude abnormal lymphoplasia. Microscopic examination showed cells exhibiting diversity with infiltration of scattered plasma cells, histiocytes, and immunoblasts. Genomic tests found a deletion mutation, which has been reported earlier. This finding also suggested that pathologically diagnosed ALH already has malignant properties, indicating that it should be treated as such to refine prognosis. Statistically, the differences in Bcl10 gene mutation were significant among subjects with MALT lymphoma, ALH, RLH, and normal peripheral lymph nodes.

This study found that Bcl10 had different novel mutations in different types of disease and that the distribution of the mutations in MALT lymphoma, ALH, and RLH was consistent with pathological type. This information may help clinicians make earlier and more sensitive estimations of disease course at the genetic level. In the 11 cases with new mutations, the mutant in 5 cases was a $\mathrm{G} \rightarrow \mathrm{A}$ point mutation at nucleotide 638 in the exon, changing Gly 213 to Glu in the protein coding region with a $45 \%$ mutation rate. The next was a 129 -bp deletion at nucleotide 294 in the exon, which truncated the 233-amino acid protein product to 99 amino acids (GenBank accession No. EF189176). A T $\rightarrow$ C point mutation at nucleotides 308, 368, and 5 in the exon changed Val 103 to Ala, Glu 123 to Gly, and Glu 2 to Gly, respectively. An $\mathrm{A} \rightarrow \mathrm{G}$ point mutation at nucleotides 115, 374, and 186 changed Cys 58 to Arg, Ben 125 to Cyp, and Arg 62 to Ala.

Compared with the mutation types published by Willis et al. (1999), the mutations in MALT-type OAL in Chinese people are mainly point mutations. New mutations were also found in ALH and RLH, suggesting that the mutation of the wild-type Bcl10 plays an important role in the progression of ALH and RLH to MALT lymphoma. Further study is needed to investigate the mutations that might lead to changes in biological behavior in tumor cells and their roles in the activation of the NF- $\mathrm{kB}$ intracellular signal pathway. Examination of fluorescence expression of $\mathrm{Bcl10}$ in this study showed that in MALT lymphoma, the NF- $\kappa$ B response factor of I $\alpha$ displays 
diffuse expression in the cytoplasm, whereas Bcl10 might not be expressed in samples that express I $\alpha$. Both Bcl10 and NF- $\kappa$ B were expressed in 14 cases of MALT lymphoma.

Currently, activation of the NF- $\mathrm{BB}$ signal pathway caused by the mutation and nuclear expression of Bcl10 is believed to play an important role in the tumorigenic mechanism of MALT lymphoma (Hosokawa and Seto, 2004). The activation of the NF- $\kappa B$ pathway by Bcl10, leading to the degradation of I $\kappa \mathrm{B}$ phosphorylation and $\kappa \mathrm{B}$ translocation to the nucleus, in turn triggering transcription, is an important mechanism of tumorigenesis. Few studies about local ocular lesions in systemic MALT lymphoma have been published, and most reports focus on retrospective investigations of clinical parameters and prognosis from clinical data and follow-up. Only minor attention has been paid to pathogenesis with respect to molecular pathology, biology, and intracellular signal transduction pathways (Garrison et al., 2009). The abnormal expression and mutants of Bcl10 in MALT-type OAL are closely related to various anomalies of karyological chromosomes and are usually the last targeted object of each chromosomal karyotypic abnormality. Bcl10 expression can be found in various chromosomal anomalies, but the mechanism through which Bcl10 mutation leads MALT1 oligomerization and activates the NF- $\mathrm{BB}$ essential modulator in the NF- $\kappa \mathrm{B}$ pathway, as well as the specific signaling pathway of the transcription changes induced by $\kappa \mathrm{B}$ translocation into the nucleus, remain unclear (Prasad et al., 2010).

This study is the first to detect and confirm Bcl10 expression in OAL, ALH, and RLH completely in Chinese people. We uncovered novel mutations and determined the relationship between Bcl10 and NF- $\mathrm{KB}$ expression using laser confocal fluorescence. This study provides new evidence and reference for the role of the NF- $\mathrm{kB}$ pathway activated by Bcl10 mutation and abnormal expression in the pathogenesis of MALT lymphoma and its clinical and differential diagnosis. The results also suggest that the detection of target gene expression and mutation using molecular biological methods may provide a more accurate and sensitive index for clear clinical diagnosis.

\section{ACKNOWLEDGMENTS}

The authors thank Professor Liu Huimin (Department of Pathology, Changzheng Hospital) for providing tissue specimens and Sun Mingjuan and Zhao Lei (Department of Biochemistry, Second Military Medical University) for technical assistance.

\section{REFERENCES}

Coupland SE (2004). Lymphoproliferative lesions of the ocular adnexa. Differential diagnostic guidelines. Ophthalmologe 101: 197-215.

Du MQ (2011). MALT lymphoma: many roads lead to nuclear factor-kappab activation. Histopathology 58: 26-38.

Du MQ, Peng H, Liu H, Hamoudi RA, et al. (2000). BCL10 gene mutation in lymphoma. Blood 95: 3885-3890.

Garrison JB, Samuel T and Reed JC (2009). TRAF2-binding BIR1 domain of c-IAP2/MALT1 fusion protein is essential for activation of NF-kappaB. Oncogene 28: 1584-1593.

Hamoudi RA, Appert A, Ye H, Ruskone-Fourmestraux A, et al. (2010). Differential expression of NF-kappaB target genes in MALT lymphoma with and without chromosome translocation: insights into molecular mechanism. Leukemia 24: 1487-1497.

Hosokawa Y and Seto M (2004). Nuclear factor kappaB activation and antiapoptosis in mucosa-associated lymphoid tissue lymphoma. Int. J. Hematol. 80: 215-223.

Kingeter LM and Schaefer BC (2010). Malt1 and cIAP2-Malt1 as effectors of NF-kappaB activation: kissing cousins or distant relatives? Cell Signal. 22: 9-22. 
Marcus R (2007). Pathogenesis of MALT lymphoma: implications for risk stratification and therapy. Leuk. Lymphoma 48: 2087-2088.

McKelvie PA (2010). Ocular adnexal lymphomas: a review. Adv. Anat. Pathol. 17: 251-261.

Misdraji J, Harris NL, Hasserjian RP, Lauwers GY, et al. (2011). Primary follicular lymphoma of the gastrointestinal tract. Am. J. Surg. Pathol. 35: 1255-1263.

Prasad S, Ravindran J and Aggarwal BB (2010). NF-kappaB and cancer: how intimate is this relationship. Mol. Cell Biochem. 336: 25-37.

Rohatiner A, d'Amore F, Coiffier B, Crowther D, et al. (1994). Report on a workshop convened to discuss the pathological and staging classifications of gastrointestinal tract lymphoma. Ann. Oncol. 5: 397-400.

Rosebeck S, Lucas PC and McAllister-Lucas LM (2011). Protease activity of the API2-MALT1 fusion oncoprotein in MALT lymphoma development and treatment. Future Oncol. 7: 613-617.

Sagaert X, De Wolf-Peeters C, Noels H and Baens M (2007). The pathogenesis of MALT lymphomas: where do we stand? Leukemia 21: 389-396.

Sun W and Yang J (2010). Molecular basis of lysophosphatidic acid-induced NF-kappaB activation. Cell Signal. 22: 1799-1803.

Thieblemont C, Bastion Y, Berger F, Rieux C, et al. (1997). Mucosa-associated lymphoid tissue gastrointestinal and nongastrointestinal lymphoma behavior: analysis of 108 patients. J. Clin. Oncol. 15: 1624-1630.

Willis TG, Jadayel DM, Du MQ, Peng H, et al. (1999). Bcl10 is involved in $\mathrm{t}(1 ; 14)(\mathrm{p} 22 ; \mathrm{q} 32)$ of MALT B cell lymphoma and mutated in multiple tumor types. Cell 96: 35-45.

Wu CJ and Ashwell JD (2008). NEMO recognition of ubiquitinated Bcl10 is required for T cell receptor-mediated NFkappaB activation. Proc. Natl. Acad. Sci. U. S. A. 105: 3023-3028.

Ye H, Gong L, Liu H, Hamoudi RA, et al. (2005). MALT lymphoma with t(14;18)(q32;q21)/IGH-MALT1 is characterized by strong cytoplasmic MALT1 and BCL10 expression. J. Pathol. 205: 293-301.

Zhou H, Wertz I, O'Rourke K, Ultsch M, et al. (2004). Bcl10 activates the NF-kappaB pathway through ubiquitination of NEMO. Nature 427: 167-171. 